\title{
Improvement of Electrochemical Characteristics of Natural Graphite Negative \\ Electrode Coated with Polyacrylic Acid in Pure Propylene Carbonate Electrolyte
}

Koichi Ui, Shinei Kikuchi, Fuminobu Mikami, Yoshihiro Kadoma, and Naoaki Kumagai*

Department of Frontier Materials and Functional Engineering,

Graduate School of Engineering, Iwate University

- Article type

- *Corresponding author

- Business Affiliation

- Complete postal address

- Phone and fax number

- E-mail address

\section{Short Communication.}

Professor Naoaki KUMAGAI (M)

Iwate University

4-3-5 Ueda, Morioka, Iwate 020-8551, JAPAN

$+81-19-621-6328$

nkumagai@iwate-u.ac.jp or kui@iwate-u.ac.jp 


\begin{abstract}
In order to improve the negative electrode characteristics of a graphite electrode in a propylene carbonate (PC) - containing electrolyte, we have prepared a graphite negative electrode coated with a water-soluble anionic polymer as a binder for composite graphite electrodes. The electrochemical characteristics of the coated graphite were evaluated by cyclic voltammetry and charge-discharge cycle tests. The coated graphite negative electrode showed a stable $\mathrm{Li}^{+}$ion intercalation / deintercalation reaction without the exfoliation of the graphene layers caused by the co-intercalation of the PC solvent in the $\mathrm{LiClO}_{4}$ / PC solution. The charge-discharge characteristic of the coated graphite negative electrode in a PC - containing electrolyte was almost the same as that in ethylene carbonate-based electrolyte.
\end{abstract}

Keywords: Lithium-ion battery, polyacrylic acid, propylene carbonate electrolyte, natural graphite, negative electrode

\title{
1. Introduction
}

Ethylene carbonate (EC) - based solutions containing a lithium salt have been widely used as the electrolyte for lithium-ion batteries using a carbon negative electrode 
over the past decade. They cause the formation of a protective film, the so-called solid electrolyte interface (SEI), on the surface of the graphite particles through the reductive decomposition of the solvent at around $1.0 \mathrm{~V}$ vs. $\mathrm{Li} / \mathrm{Li}^{+}$during the first charging process[1, 2]. It has been generally accepted that the SEI layer plays an important role of allowing the charge-discharge reaction involving $\mathrm{Li}^{+}$ion intercalation / deintercalation to occur after the second cycle. In contrast, in PC-based solutions, electrochemical $\mathrm{Li}^{+}$ion intercalation into graphite layers does not occur due to the co-intercalation and significant decomposition reaction of PC molecules at around $1.0 \mathrm{~V}$ vs. $\mathrm{Li} / \mathrm{Li}^{+}$causing exfoliation of the graphene layers. Therefore, the charge-discharge cyclings of a graphite negative electrode are poor in a PC-based solution [3]. However, it is advantageous to use pure PC from the viewpoint of the battery operation temperature especially at a lower temperature because the melting point of PC ( $m p$ $\left.-49^{\circ} \mathrm{C}\right)$ is lower than that of EC ( $\left.m p 37^{\circ} \mathrm{C}\right)$. Some attempts using additives in the electrolyte have been reported to allow the successful operation of graphite as a negative electrode in a PC-based solution. It has been recently reported that the addition of vinylene carbonate [4] or crown ether [5] to a PC-based solution significantly suppresses the solvent decomposition and graphite exfoliation, enabling $\mathrm{Li}^{+}$ions to be intercalated into the graphite. It appears that these additives produce a stable SEI layer 
on the graphite surface, which prevents the co-intercalation and decomposition of the PC molecules, allowing the desolvated $\mathrm{Li}^{+}$ions to be intercalated [6]. However, such an effective surface film is not formed in a PC-based solution [7]. Additionally, these additives could affect the positive electrode because these materials are directly added to the electrolyte. The improvement of the negative electrode characteristics in a pure PC solution is strongly urged without the use of additives.

We now propose a coating of a water-soluble polymer on the graphite particles without using additives. We assume that the polymer film can prevent the intercalation of a solvent molecule into the graphite layer in a PC solution. In this study, we have focused our attention on polyacrylic acid (PAA) as a binder. Recently, it has been reported that both the $\mathrm{LiCoO}_{2}$ and graphite powders could be dispersed by PAA-NH 4 used as a binder, resulting in a decrease of the powder aggregation and an increase in the contact area between $\mathrm{LiCoO}_{2}$ and graphite [8]. The electrode coating on the graphite particle using a PAA binder was carried out in order to enable the reversible charge $\left(\mathrm{Li}^{+}\right.$ ion intercalation) and discharge (deintercalation) reaction of the graphite negative electrode in a pure PC solution.

\section{Experimental}


The graphite electrode was prepared as follows. Natural graphite powder (Kansai Coke and Chemical Co., NG-3) and PAA (Wako Pure Chemical Industries, Ltd.; average molecular weight, 1,000,000) as a binder were mixed at the ratio of $90: 10$ (by mass), and the mixture was then slurried using distilled water. The slurry was then coated on a Ni mesh (Tokyo Screen Co., 100 mesh, $10 \mathrm{~mm} \times 10 \mathrm{~mm}$ ). Prior to use, the electrode was pressed and then dried in a vacuum at $80{ }^{\circ} \mathrm{C}$ for $12 \mathrm{~h}$. The electrode was also prepared using poly(vinylidene difluoride) (Kureha. Co., PVdF) as a binder for comparison.

The electrochemical measurements were carried out using a three-electrode cell. The graphite electrode was used as the working electrode, and lithium metal foils were used as the counter and reference electrodes. A $1 \mathrm{~mol} \mathrm{dm}^{-3}(\mathrm{M})$ solution of $\mathrm{LiClO}_{4}$ in EC : DEC (50 : 50 vol.\%) (Mitsubishi Chemical Co.; water content under 30 ppm) and a $1 \mathrm{M}$ solution of $\mathrm{LiClO}_{4}$ in PC (Mitsubishi Chemical Co.; water content under 30 ppm) were used as the electrolytes. The cells were assembled in a glove box (Miwa Mfg Co., Ltd., DBO-1NKP-1U-2) filled with dry argon at room temperature.

Cyclic voltammetry (CV) was performed using a computer-controlled electrochemical measuring system (Hokuto Denko, HZ-3000). The scan rate of the CV was $0.5 \mathrm{mV} \mathrm{s}^{-1}$ between 0 and $2.0 \mathrm{~V}$ vs. $\mathrm{Li} / \mathrm{Li}^{+}$. The charge-discharge cycle tests were 
performed using an automatic battery charging-discharging instrument (Hokuto Denko, HJR-1010mSM8) at a current density of $175 \mathrm{~mA} \mathrm{~g}^{-1}$ (0.5 C rate) between 0 and $2.0 \mathrm{~V}$ vs. $\mathrm{Li} / \mathrm{Li}^{+}$.

The crystal structure and surface morphology of the samples before and after the charge-discharge cycle tests were examined by $\mathrm{X}$-ray diffraction (XRD) using an X-ray diffractometer (Rigaku Denki, RINT2200, AFC7) with Cu Ka radiation $(\lambda=0.15418$ $\mathrm{nm}$ ) and scanning electron microscopy (Hitachi, N-2250NII, SEM). For the ex-situ XRD measurements of the graphite electrodes, the electrode was charged at a constant current of $175 \mathrm{~mA} \mathrm{~g}^{-1}$ up to the given potentials, and the cells were then disassembled in the glove box to obtain the sample electrode. The obtained electrodes were then washed with DEC or PC (Wako Chemical Industries, Ltd., superfine quality), and packaged in propylene film (Rigaku Denki, Cell sheet) to prevent the contact of the sample with air.

\section{Results and discussion}

The CV was measured in $1 \mathrm{M} \mathrm{LiClO}_{4} / \mathrm{EC}:$ DEC (50:50 vol.\%) in order to investigate the electrochemical redox behavior of the NG-3 electrode using PAA (10 wt.\%) as the binder (Fig. 1, solid line). The CV of the NG-3 electrode using PVdF (10 wt.\%) as the binder is also shown (Fig. 1, dotted line). In the case of PVdF, a reduction 
current was observed at around $0.7 \mathrm{~V}$. The reduction peak is considered to be due to the decomposition of the electrolyte. In contrast, it was found that the decomposition of the electrolyte was significantly restrained using PAA because the peak scarcely appeared $[1,2]$. These results indicated that the binding state with PAA is different from that with PVdF. For example, when gelatin was used as a binder, it was reported that the irreversible capacity decreased $[9,10]$. It was considered that a more uniform and thinner SEI layer was formed by coating the gelatin on the surface of the graphite, preventing the direct contact between the graphite and electrolyte. A similar effect was seen using a PAA binder, and the decomposition reaction of an electrolyte is considered to be suppressed in this case. The charge-discharge curves in the first cycle of the NG-3 negative electrodes are shown in Fig. 2. For PVdF, the first discharge capacity was 344 $\mathrm{mAh} \mathrm{g}^{-1}$, and the charge-discharge efficiency was ca. $76.6 \%$. On the other hand, in the case of PAA, the first discharge capacity was $356 \mathrm{mAh} \mathrm{g}^{-1}$ and the charge-discharge efficiency was ca. $84.6 \%$. The electrode characteristics when coated with PAA were then superior to those of the electrode coated with PVdF because the presence of PAA reduced the irreversible capacity loss. The cycle performance of the NG-3 electrode coated with 10 wt. \% PAA was evaluated (Fig. 3). A good cycling stability was observed during 50 cycles in an EC-based solution. Based on these results, it was found 
that PAA is effective as a binder.

Next, the CV was measured in $1 \mathrm{M} \mathrm{LiClO}_{4}$ / PC to investigate the electrochemical redox behavior of the NG-3 electrode using PAA (10 wt.\%) as a binder (Fig. 4, solid line). The CV of the NG-3 electrode using PVdF (10 wt.\%) as a binder is also shown (Fig. 4, dotted line). For the PAA, the coupled redox peaks were clearly observed in the potential range from 0 to $0.3 \mathrm{~V}$. For the PVdF, the oxidation current was not observed though the reduction current dramatically increased from $c a .0 .8 \mathrm{~V}$, showing that the decomposition reaction of a PC solution occurred. The charge-discharge curves of both electrodes using a constant current density of $175 \mathrm{~mA} \mathrm{~g}^{-1}$ are shown in Fig. 5. The first charge curve of the electrode coated with PVdF showed a potential plateau at $c a .0 .8 \mathrm{~V}$. Around this potential, the co-intercalation of $\mathrm{Li}^{+}$ion solvated with PC molecules occurs, resulting in the reductive decomposition of PC as described in the literature [11]. It was considered that the graphite layer was exfoliated because $\mathrm{Li}^{+}$ions and PC molecules were co-intercalated into it as described below. In contrast, the electrode coated with the PAA-coated graphite showed stable charge-discharge characteristics. The first discharge capacity was $350 \mathrm{mAh} \mathrm{g}^{-1}$, and the charge-discharge efficiency was ca. $82.8 \%$. In order to confirm that $\mathrm{Li}^{+}$ions were intercalated within the graphite layers during charging, the ex-situ XRD patterns of the NG-3 electrode coated with PAA during the first charge 
process were examined (Fig. 6). The (002) and (004) peaks observed at 26.5 ( $d=337$ $\mathrm{pm})$ and $54.6^{\circ}(\mathrm{d}=168 \mathrm{pm})$, respectively, were ascribed to the diffraction peaks of the natural graphite before charging. Since the peak intensity and d value remained unchanged after charging to $0.8 \mathrm{~V}$, it is clear that the co-intercalation of $\mathrm{Li}^{+}$ions and PC molecules does not occur. The diffraction peaks of the natural graphite shifted to the lower positions of $24.0^{\circ}(\mathrm{d}=370 \mathrm{pm})$ and $49.2^{\circ}(\mathrm{d}=185 \mathrm{pm})$ corresponding to (001) and (002), respectively, after charging to $0.02 \mathrm{~V}$. This indicates an increase in the distance between the graphite layers due to the $\mathrm{Li}^{+}$ion intercalation. Moreover, the average distance between layers obtained from the peaks $\left(24.0\right.$ and $\left.49.2^{\circ}\right)$ was $370 \mathrm{pm}$, which agrees with the literature [12]. These values correspond to the formation of the stage 1 intercalation compound $\mathrm{LiC}_{6}$, revealing that desolvated $\mathrm{Li}^{+}$ions were intercalated between the graphite layers in a pure PC solution. The cycle performances of the NG-3 electrodes coated with 10 wt. \% PAA and 10 wt. \% PVdF are shown in Fig. 7. The reversible discharge capacities of the NG-3 electrode coated with PAA were maintained during 10 cyclings at $c a$. 350 $\mathrm{mAh} \mathrm{g}^{-1}$. In contrast, the charge-discharge reaction did not occur in the case of PVdF. The SEM images of the NG-3 particles coated with (a) PVdF and (b) PAA as binders after 10 cycling in a PC solution are shown in Fig. 8. The exfoliation of the graphene layer was observed when the 
electrode coated with PVdF was polarized to the negative potential of $0.8 \mathrm{~V}$ (Fig. 8a). This is caused by the co-intercalation of the $\mathrm{Li}^{+}$ions solvated by PC, resulting in the reductive decomposition of the PC molecules. On the other hand, the particle shape of the graphite using the PAA binder was maintained after 10 cycles (Fig. 8b). These results indicated that the original graphite structure is maintained during repeated intercalations of the desolvated $\mathrm{Li}^{+}$ions without exfoliation of the layers.

Based on these results, the natural graphite negative electrode using a PAA binder shows a reversible intercalation reaction of $\mathrm{Li}^{+}$ions during cyclings in a PC solution, so that the electrolyte consisting of a pure PC solution could be used as the electrolyte for lithium-ion secondary batteries.

\section{Conclusions}

The electrochemical characteristics of a natural graphite electrode coated with PAA in the electrolyte consisting of a pure propylene carbonate solution have been studied. First, the electrode characteristics of an NG-3 electrode coated with 10 wt. \% PAA or PVdF were evaluated in an EC-based solution. PAA was found to be effective as a binder because the characteristics of the electrode coated with PAA were superior to those of the electrode coated with PVdF. Moreover, the electrode coated with PAA 
enabled the reversible charge $\left(\mathrm{Li}^{+}\right.$ion intercalation) and discharge (deintercalation) reaction in a pure PC solution and maintained the initial discharge capacity during 10 cycles. It was confirmed that the particle shape of graphite was maintained after the 10th cycle based on SEM observation. It would be considered that the surface film consisting of PAA binder on the graphite electrode prevents the intercalation of solvated $\mathrm{Li}^{+}$ions followed by exfoliating the graphite layers. These results lead to the conclusion that a pure PC solution should be used as the electrolyte for lithium-ion batteries because the natural graphite negative electrode using PAA as a binder works quite effectively.

\section{References}

[1] E. Peled, J. Electrochem. Soc., 126 (1979) 2047.

[2] R. Fong, U. von Sacken, and J. R Dahn, J. Electrochem. Soc., 137 (1990) 2009.

[3] A. N. Dey and B. P. Sulliva, J. Electrochem. Soc., 117 (1970) 222.

[4] S. -K. Jeong, M. Inada, R. Mogi, Y. Iriyama, T. Abe, and Z. Ogumi, Langmuir., 17 (2001) 8281.

[5] Z. X. Shu, R. S. McMillan, and J. J. Murray, J. Electrochem. Soc., 140 (1993) 922.

[6] M. Arakawa and J. I. Yamaki, J. Electroanal. Chem., 219 (1987) 273. 
[7] Z. Ogumi and M. Inada, Bull. Chem. Soc. Jpn., 71 (1998) 521.

[8] C. C. Li, J. T. Lee, and X. W. Peng, J. Electrochem. Soc., 153 (2005) A809.

[9] M. Gaberscek, M. Bele, J. Drofenik, R. Dominko, and S. Pejovnik, Electrochem. Solid-State Lett., 3 (2000) 171.

[10] R. Dominko, M. Gaberscek, M. Bele, J. Drofenik, E. M. Skou, A. Würsig, P. Novák, and J. Jamnik, J. Electrochem. Soc., 151 (2004) 1058.

[11] G. C. Chung, H. J. Kim, S. I. Yu, S. H. Jun, J. w. Choi, and M. H. Kim, J. Electrochem. Soc., 147 (2000) 4391.

[12] J. R Dahn, Phys. Rev. B, 44 (1991) 9170. 


\section{All figure captions}

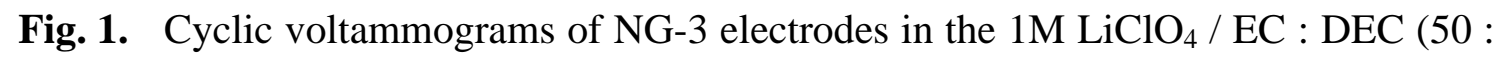
50 vol.\%): Potential range: $0.0-2.0 \mathrm{~V}$ vs. $\mathrm{Li} / \mathrm{Li}^{+}$, Scan rate : $0.1 \mathrm{mV} \mathrm{s}{ }^{-1}$; $(-$ ) PAA10 wt.\% ; ( …........... ) PVdF 10 wt.\%.

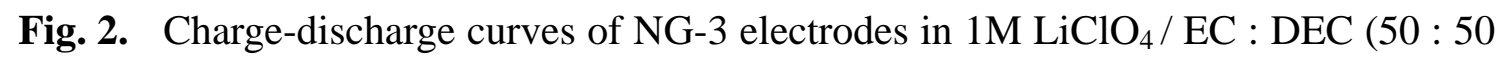
vol.\%) in the first cycle: C. D., $175 \mathrm{~mA} \mathrm{~g}^{-1}$ (0.5 C); ( — ) PAA10 wt.\% ; ( …........... ) PVdF 10 wt.\%.

Fig. 3. Cycle performance of NG-3 electrode coated with 10 wt. \% PAA as binder tested in $1 \mathrm{M} \mathrm{LiClO}_{4}$ / EC : DEC (50 : 50 vol.\%): Potential range : 0.0-2.0 V vs. $\mathrm{Li} / \mathrm{Li}^{+}$, C. D., 175 mA g ${ }^{-1}$ (0.5 C); ( $\left.\square\right)$ Charge; (O) Discharge.

Fig. 4. Cyclic Voltammograms of NG-3 electrodes in $1 \mathrm{M} \mathrm{LiClO}_{4} / \mathrm{PC}$ : Potential range : 0.0-2.0 V vs. $\mathrm{Li} / \mathrm{Li}^{+}$, Scan rate : $0.1 \mathrm{mV} \mathrm{s}^{-1} ;($ ( )PAA10 wt.\% ; ( …......... ) $)$ PVdF10 wt.\%.

Fig. 5. Charge-discharge curves of NG-3 electrodes in the $1 \mathrm{M} \mathrm{LiClO}_{4} / \mathrm{PC}$ in the first cycle: C. D., $175 \mathrm{~mA} \mathrm{~g}^{-1}(0.5 \mathrm{C}) ;($ — $)$ PAA10 wt.\% ; ( …........... ) PVdF10 wt.\%.

Fig. 6. Ex-situ XRD patterns of NG-3 electrode coated with PAA as binder during the 
charge process: (a) packing film, (b)before charging, charging down to (c)0.8, (d)0.2, and (e)0.02 V vs. $\mathrm{Li} / \mathrm{Li}^{+}$.

Fig. 7. Cycle performance of NG-3 electrodes coated with PAA and PVdF in 1M $\mathrm{LiClO}_{4}$ / PC: Potential range : 0.0-2.0 V vs. Li / $\mathrm{Li}^{+}$, C. D., 175 mA g ${ }^{-1}$ (0.5 C) ; (О) PAA10 wt.\% ; ( $\mathbf{\Delta})$ PVdF10 wt.\%.

Fig. 8. SEM images of NG-3 particles coated with (a) PVdF and (b) PAA as binder after ten cycles. 


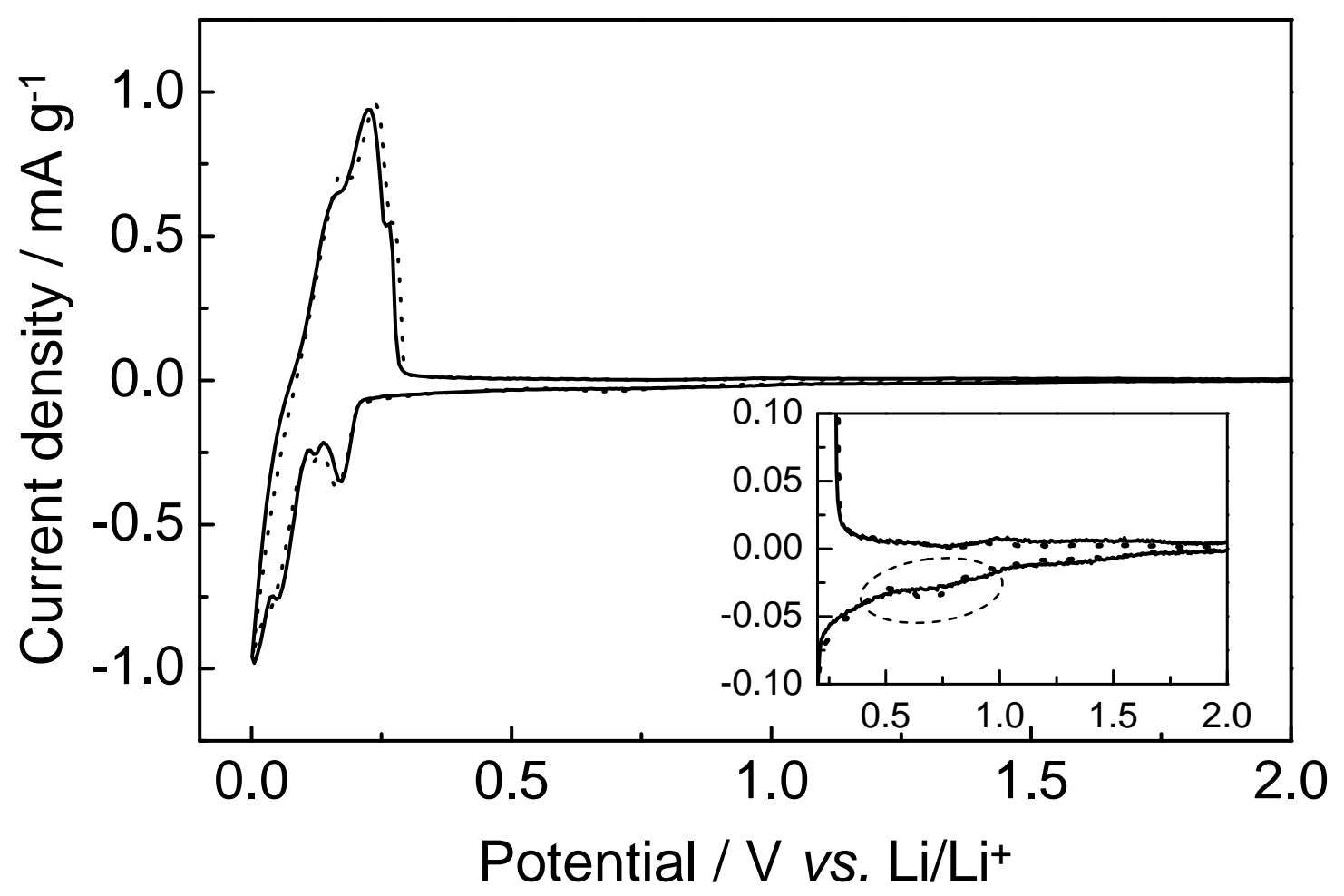

Fig. 1 Cyclic voltammograms of NG-3 electrodes in the $1 \mathrm{M} \mathrm{LiClO}_{4} / \mathrm{EC}$ :DEC (50:50 vol.\%).

Potential range: $0.0-2.0 \mathrm{~V}$ Vs. $\mathrm{Li} / \mathrm{Li}^{+}$, Scan rate $: 0.5 \mathrm{mV}$ $\mathrm{s}^{-1} ;(\longrightarrow$ ) PAA10 wt.\% ; (.............. ) PVdF 10 wt.\% 


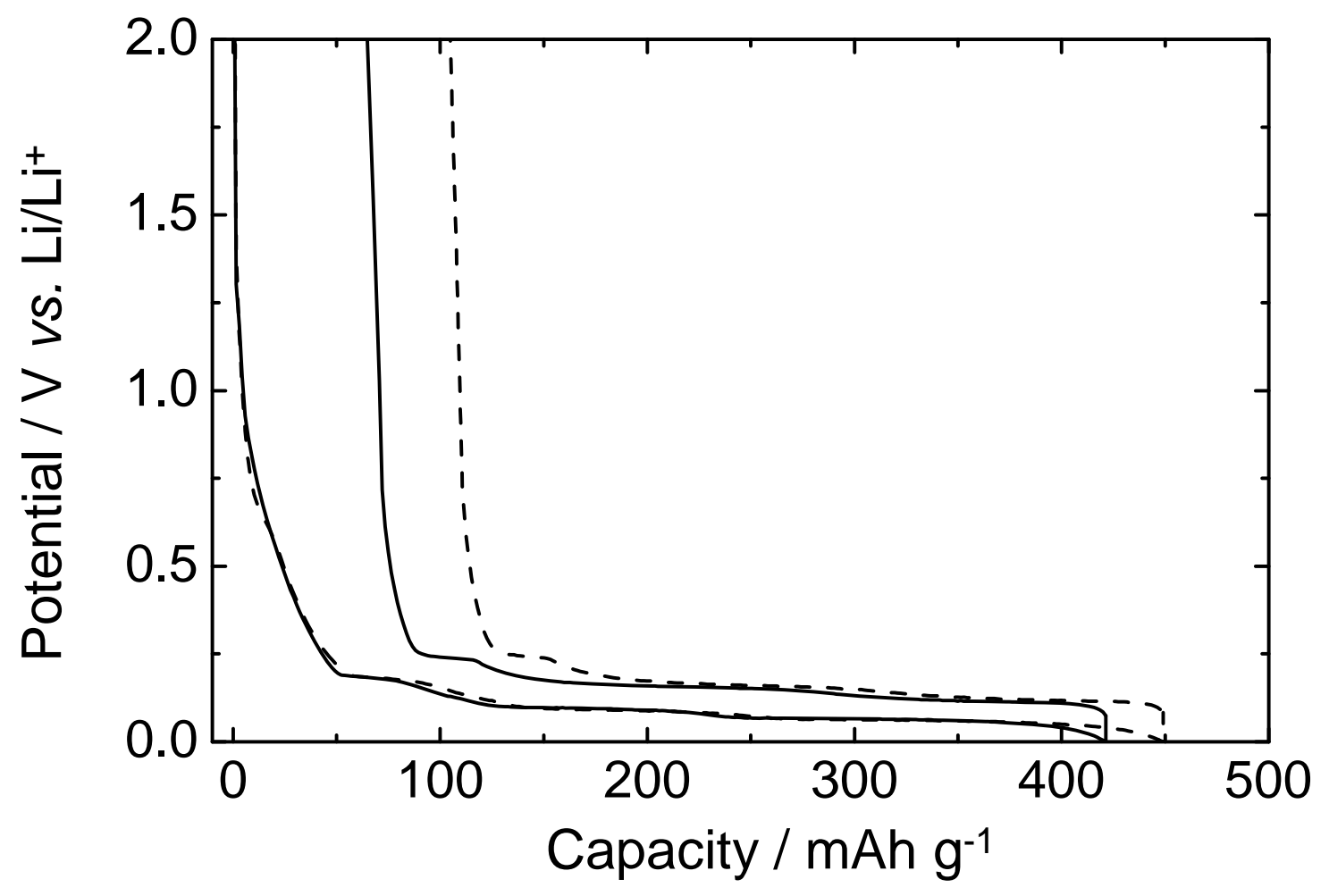

Fig. 2 Charge-discharge curves of NG-3 electrodes in $1 \mathrm{M} \mathrm{LiClO}_{4} / \mathrm{EC}: \mathrm{DEC}(50: 50 \mathrm{vol} . \%)$ in the first cycle. C. D. : $175 \mathrm{~mA} \mathrm{~g}^{-1}(0.5 \mathrm{C})$; ) PAA10 wt.\% ; ( ............... ) PVdF 10 wt.\% 


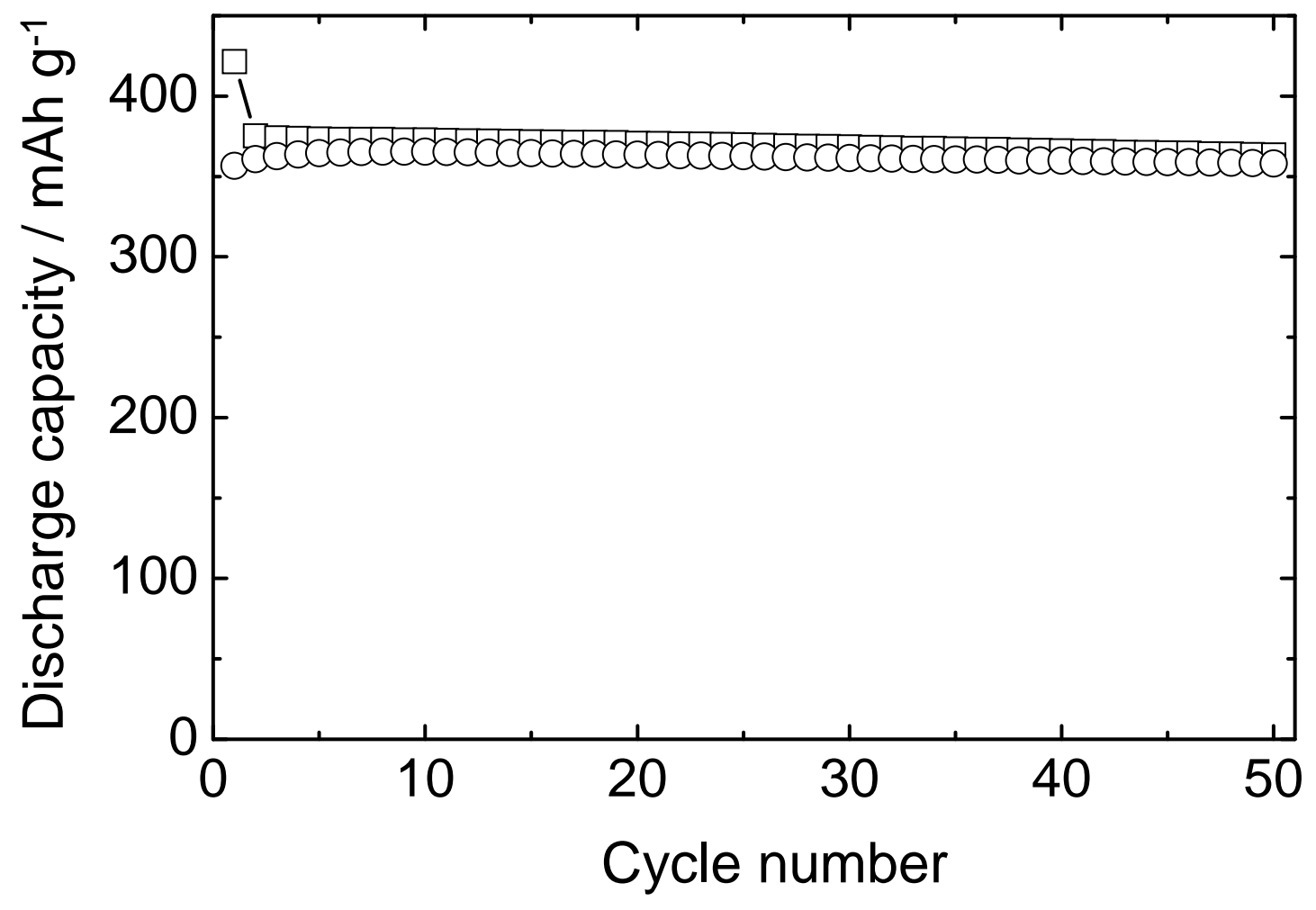

Fig. 3 Cycle performance of NG-3 electrode coated with 10 wt.\% PAA as binder tested in $1 \mathrm{M} \mathrm{LiClO}_{4} / \mathrm{EC}:$ DEC $(50: 50$ vol.\%). Potential range : 0.0-2.0 V vs. $\mathrm{Li} / \mathrm{Li}^{+}$, C. D. : $175 \mathrm{~mA}$ $\mathrm{g}^{-1}(0.5 \mathrm{C})$; $(\square)$ Charge; (O) Discharge. 


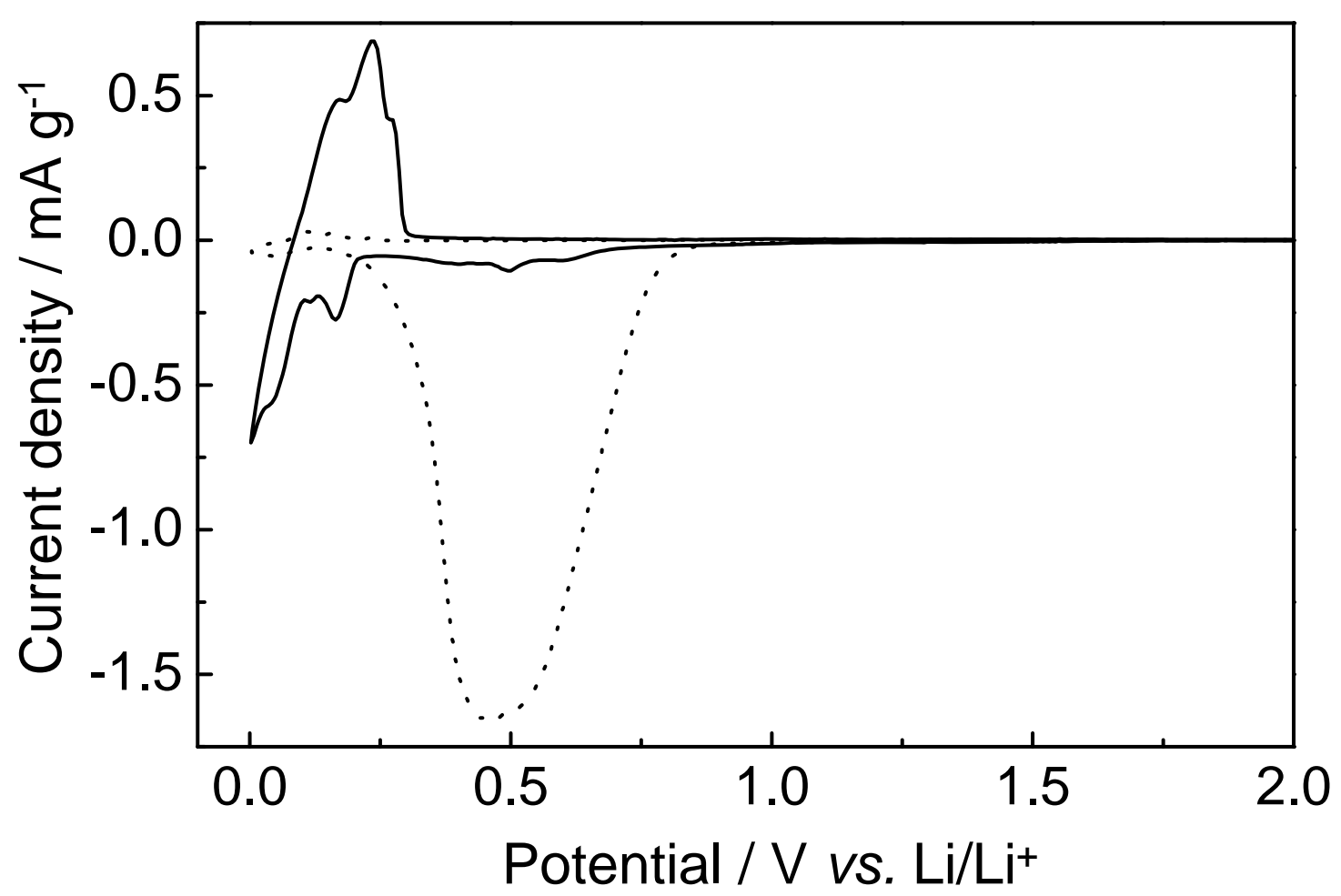

Fig. 4 Cyclic Voltammograms of NG-3 electrodes in $1 \mathrm{M} \mathrm{LiClO}_{4} / \mathrm{PC}$.

Potential range : 0.0-2.0 V vs. $\mathrm{Li} / \mathrm{Li}^{+}$, Scan rate : 0.5 $\mathrm{mV} \mathrm{s}^{-1} ;(\longrightarrow)$ PAA10 wt.\% ; (.............. ) PVdF10 wt.\% 


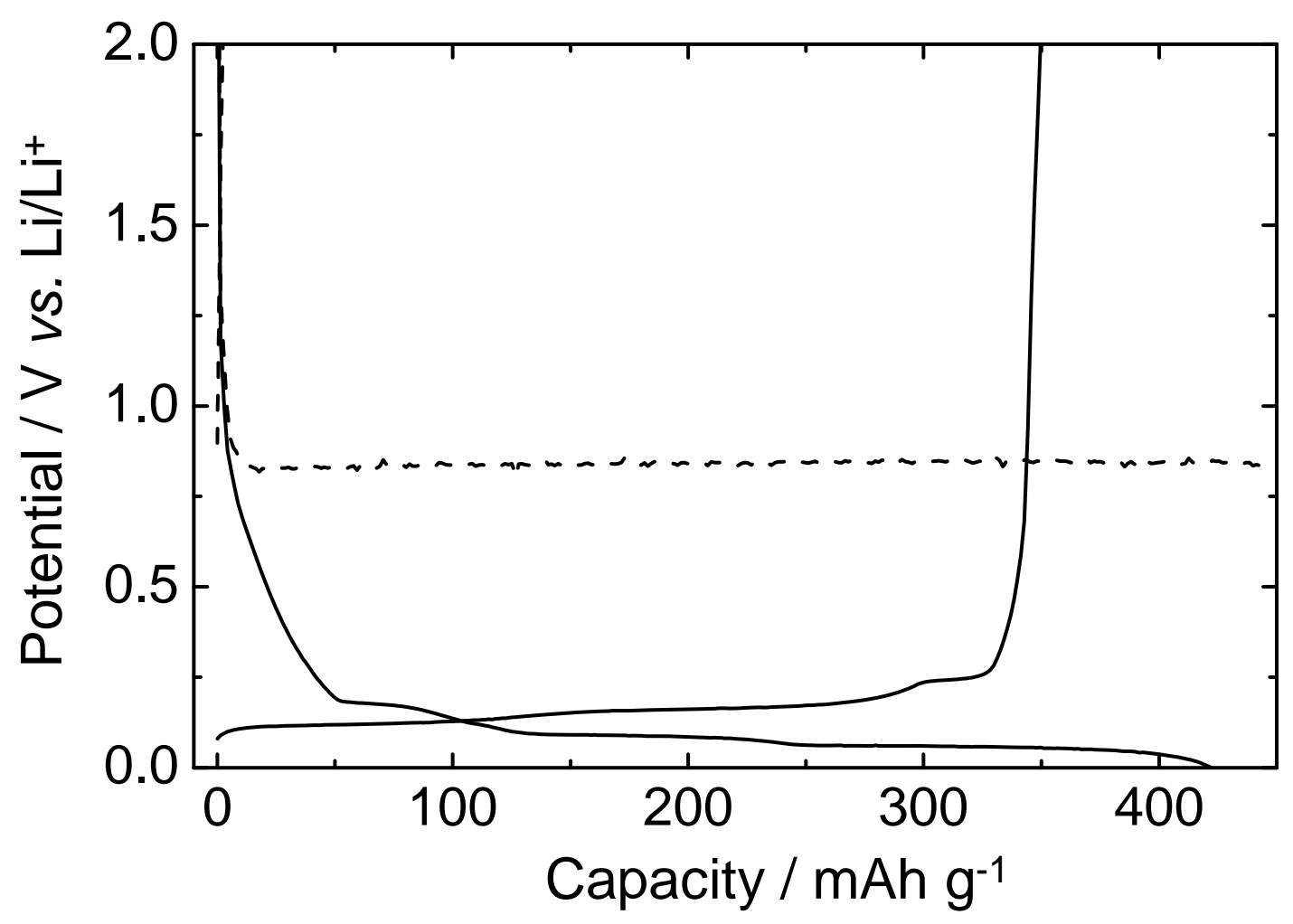

Fig. 5 Charge-discharge curves of NG-3 electrodes in the $1 \mathrm{M} \mathrm{LiClO} / \mathrm{PC}$ in the first cycle.

C. D. : $175 \mathrm{~mA} \mathrm{~g}^{-1}(0.5 \mathrm{C}) ;(\longrightarrow$ ) PAA10 wt.\% ; ( .............. ) PVdF10 wt.\% 


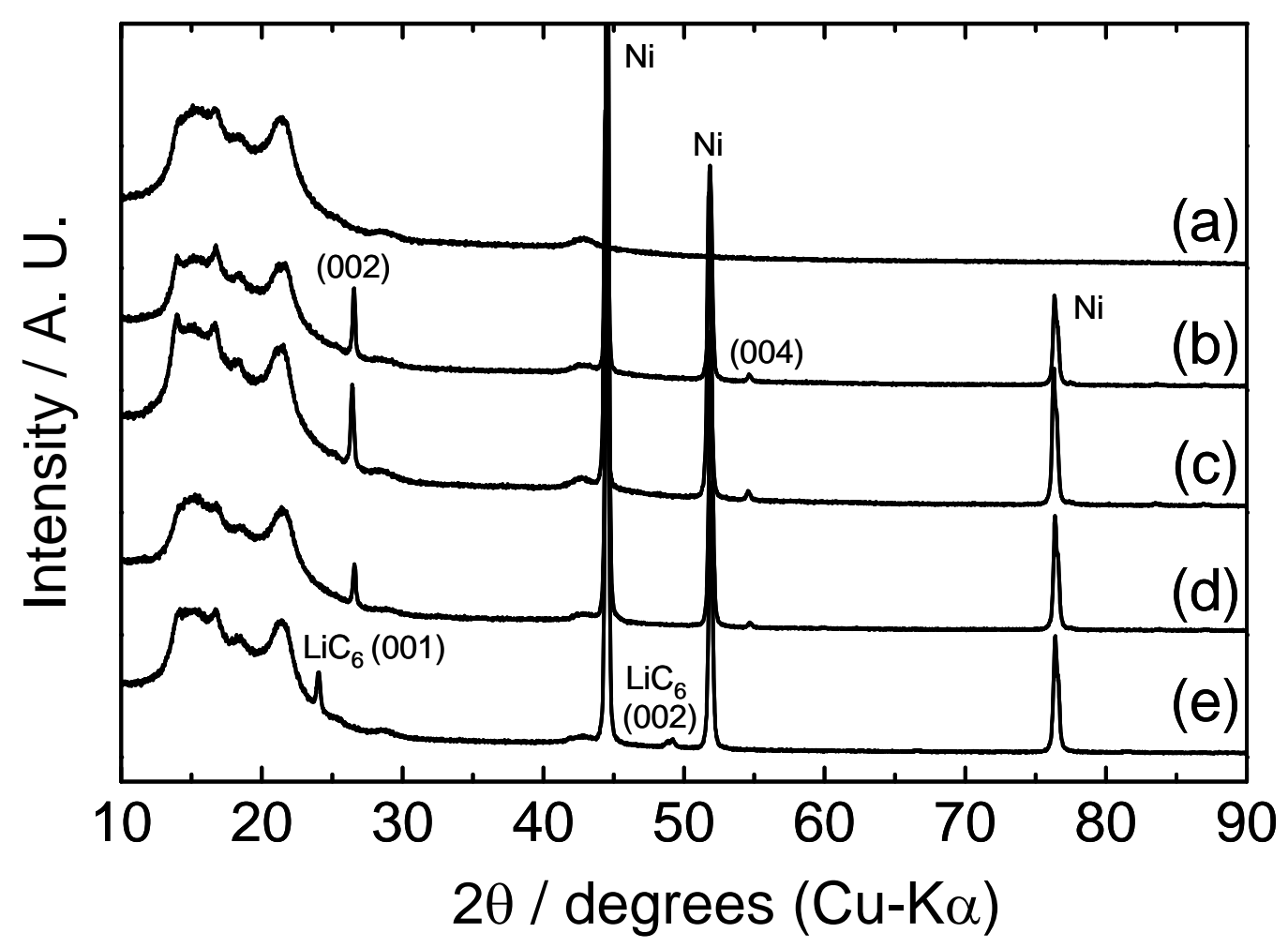

Fig. 6 EX-situ XRD patterns of NG-3 electrode coated with PAA as binder during the charge process.

(a) packing film, (b)before charging, charging down to (c) 0.8, (d)0.2, and (e) $0.02 \mathrm{~V}$ vs. $\mathrm{Li} / \mathrm{Li}^{+}$ 


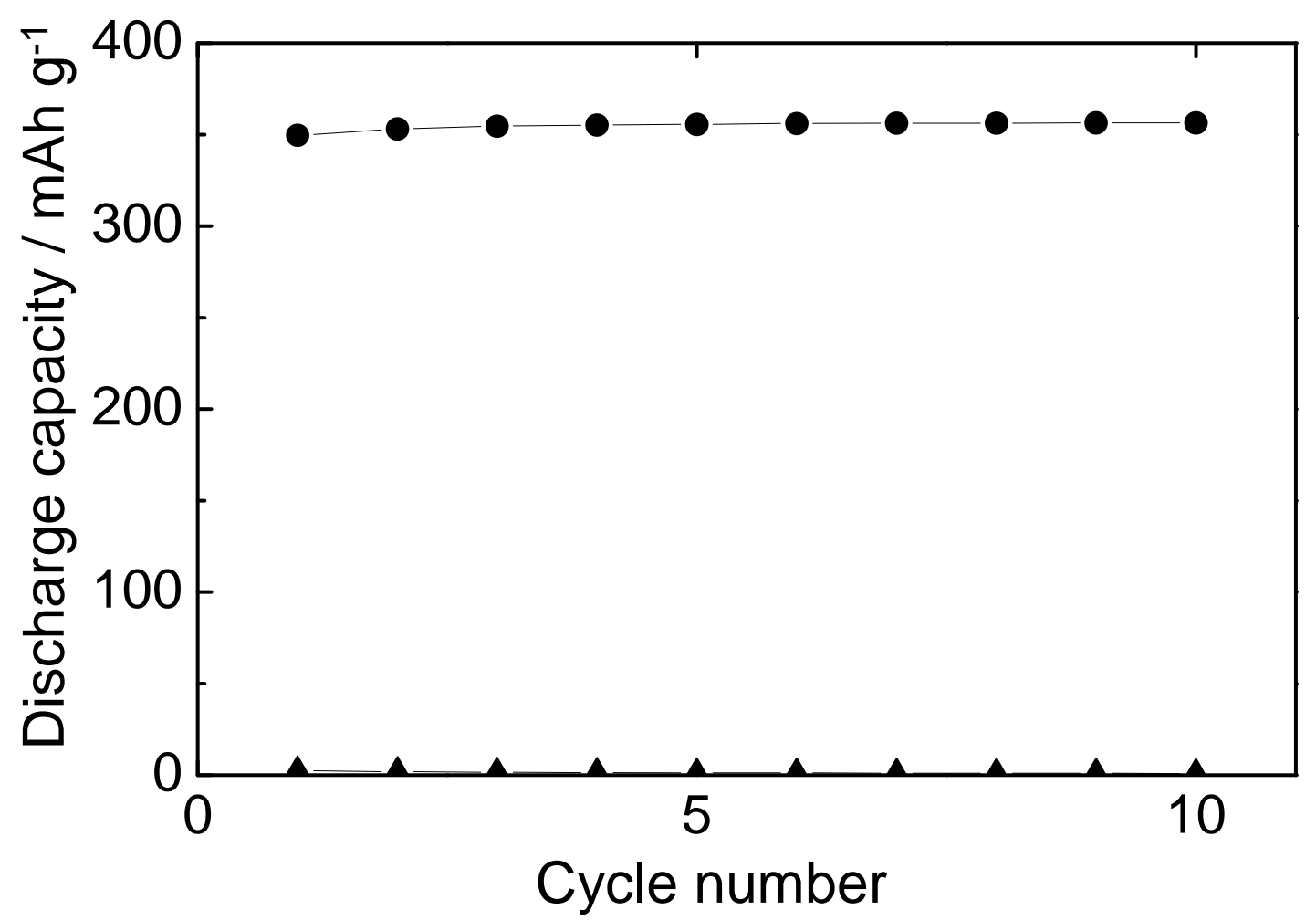

Fig. 7 Cycle performance of NG-3 electrodes coated

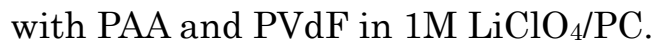

Potential range : 0.0-2.0 V vs. $\mathrm{Li} / \mathrm{Li}^{+}$, C. D. : $175 \mathrm{~mA} \mathrm{~g}^{-1}$ (0.5 C) ; (ם) PAA10 wt.\% ; (ム) PVdF10 wt.\% 

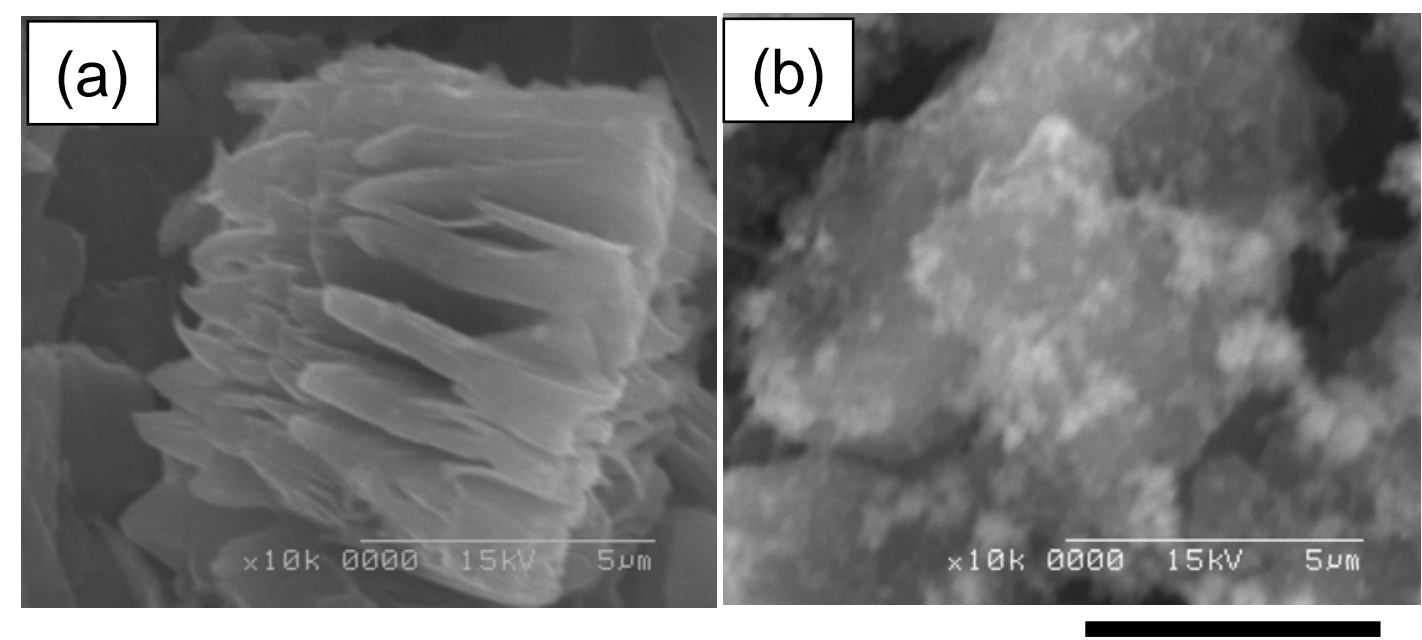

$5 \mu \mathbf{m}$

Fig. 8 SEM images of NG-3 particles coated with (a) PVdF and (b) PAA as binder after ten cycles. 